\title{
Would the Saudi Family Agree to Tell the Truth to Cancer Patient? Exploring Awareness, Perception, and Attitude to Truth Telling.
}

MOHAMMAD ABOSOUDAH ( $\square$ souda.balaji@gmail.com )

KING FAHAD MEDICAL CITY

\section{Balaji Duraisamy}

KING FAHAD MEDICAL CITY

\section{Research Article}

Keywords: tertiary care center, prognosis, efficacy of a breaking bad news system.

Posted Date: September 9th, 2021

DOl: https://doi.org/10.21203/rs.3.rs-666697/v1

License: (c) (i) This work is licensed under a Creative Commons Attribution 4.0 International License.

Read Full License 


\section{Abstract}

Aim:

To study the differences in attitude and perceptions of patients versus family members with regards to breaking bad news and full disclosure of prognosis to the patients in a tertiary care center in Saudi Arabia.

\section{Methods:}

A survey of patients and their family members was conducted in the oncology outpatient clinics using a structured questionnaire. Based on the existing prevalence of patients who wanted full disclosure, the sample size was calculated to be 143. Demographic details, diagnostic details were collected in addition to responses to questions exploring attitudes towards breaking bad news. A total of 149 patients and family members were interviewed separately.

\section{Results:}

A total of 149 patients and their family members consented to be interviewed. However, only valid responses to each question were analyzed. Overall, $75.2 \%(109 / 145)$ of patients felt that patient should be informed first as compared to $72.9 \%$ (102/140) of family members who felt the family should be informed of the bad news first. $24.3 \%$ (34) of family caregivers agreed that patients have the right to full disclosure. Both patients and family caregivers were reluctant to know details about the code status. $71.4 \%$ (95) of family caregivers and $54.3 \%$ (75) of the patients did not want the health care team to discuss details of code status and DNR. Both patients (87.1\%) and caregivers (74.3\%) agreed that the primary physician is the best person to break the bad news. Family members may be emotionally more affected than patients. They might require as much if not more support as the patients themselves during breaking bad news.

\section{Conclusions:}

There are significant differences between patient and family members regarding full disclosure of diagnosis and prognosis especially, end-of-life issues like DNR and place of death. The most stressful time for the patient was waiting for confirmatory test results. Therefore, breaking bad news support services should systematically begin even before diagnostic investigations begin. Our study points out that the majority of patients want to know the full details of diagnosis and prognosis. Discussion regarding code status has to be more structured in a way that the patient and family do not feel abandoned due to the Do Not Resuscitate status. Further study is needed to study the need and efficacy of a breaking bad news system in the hospital.

\section{Introduction:}


The bad news is something that negatively affects the patient's view of the future (3). Breaking bad news is a critical communication skill that physicians find challenging to acquire. Even though cancer diagnosis is by itself a piece of bad news, the communication of poor prognosis and survival can be intensely stressful on the patient, the family, and the physician. The news can have an adverse effect on the psychological well-being of the patient and their family. There are only a few studies comparing the patient and families' perceptions and attitudes about breaking bad news $(1,2)$ and they point out that more patients compared to the family members preferred to hear the bad news themselves. The majority of patients in Saudi Arabia (87\%) wanted to know the truth about their cancer diagnosis and as high as $90 \%$ wanted to know even if their cancer had a poor prognosis (1).

The family members with a very good intention of protecting the patient's wellbeing might resist the physician's efforts to tell the patients the truth about their diagnosis and prognosis. They usually want the physician to collude with them in hiding the entire details about the illness from the patients. Ethically, the physician is bound to respect the patient's right to know the details about their illness, for them to take a fully autonomous informed decision. This conflict between the family members and the health professional team can be detrimental to the quality of patient care. Such collusion results in poor preparation of the patient for their end of life. Patients with unfinished business are poorly prepared at the end of life and can have more terminal delirium. They might be poorly compliant with medical advice resulting in poor overall quality of life. In an audit conducted by the quality team in the cancer center at KFMC, we found that the patients and the family members were not happy with the way that the bad news was broken to them. Even though there is a written policy at KFMC to follow the SPIKES (Setting, Perception, Invitation, Knowledge, Explore Emotions, and Empathize Strategy/Summary) six steps protocol, there are obvious gaps in its implementation by the physicians.

There is a paucity of literature about the differences in attitudes and perceptions of the patients versus the caregivers. This study aims to study the differences in attitude between patients and their family caregivers and explores the possible reasons for such difference in opinion, in the specific socio-spiritualcultural background of the Saudi population. This study also attempts to describe patient/family satisfaction and opinion about the current quality of breaking bad news and communication skills of health care professionals. Though physicians agree that they have to be truthful about breaking bad news, they also feel that they are ill-equipped and diffident to break bad news (4). While literature from the middle east and the west is clear about the ethical responsibility to maintain patient rights in being truthful about cancer diagnosis, there is no clear data, especially from the middle east, on the areas for improvement in the process of breaking bad news (5-11). A study about the quality of breaking bad news in Malaysia (12) reported that though the patients were generally satisfied with the quality of breaking bad news, some areas needed improvement namely, the usage of body language, management of time and identifying patients' key areas of concerns.

The family members were concerned about the patient's possible loss of hope upon hearing the bad news while the patients felt that knowing the truth helped them plan their future more realistically and opt for less aggressive treatments. Both groups preferred that the primary physician break the bad news to 
them. According to Fallowfield and Jenkins (13), if bad news is communicated badly it can cause confusion, long-lasting distress, and resentment; if done well, it can assist understanding, acceptance, and adjustment. It is an important communication skill in the medical profession, in which formal training is rarely available. Even though such training has been shown to be helpful and effective, [4] it requires a complex communication task that requires expert verbal and non-verbal skills.

Our study focuses on comparing the perceptions and attitudes of patients with family members towards breaking bad news about cancer. This study attempts to elaborate on the patient's and families' areas of concern regarding the process of breaking bad news, which has not been well described previously. This study will also explore the attitudes of patients and family members to advance care planning especially towards the terminal phase of life, which has not been fully explored in KSA and scarce data is supporting this in literature.

\section{Methodology:}

The survey was conducted at Comprehensive Cancer Centre (CCC) from May 2017 to May 2018. All patients presenting with a cancer diagnosis to $\mathrm{CCC}$ with at least one accompanying family member will be eligible to be included in the study. The patients will be randomly selected during their visit to the medical oncology, hematology, radiation oncology, and palliative outpatients' clinic at CCC. Each of the four clinics have a daily list of patients who have an appointment, and the list is usually 6 patients per clinic on average. Randomly we chose every 3rd patient on the appointment list daily till we attain at least the requisite number of 143 patients. From the existing literature, almost $87 \%$ of the cancer patients felt that they should be told the truth and learn about their diagnosis. While presuming prevalence of $87 \%$ and an expected patient population of 800 over the study period of ten months, we will apply finite population correction at a $95 \%$ confidence interval and suggest a $5 \%$ margin of error (precision); therefore, the estimated sample size for the study is 143 (one hundred and forty-three).

The patients and the family member selected will sign the consent form, and the research assistant will conduct a 20-30-minute interview with the patient and the family member, separately for the same duration. Total (40-60 min). A validated questionnaire was developed in Arabic and validated through forward and backward translations by experts. Furthermore, the questionnaire was also translated into English, and back-translated validation procedures through expert interviews and testing the reliability through test and re-test of the questionnaire were adapted.

The questionnaire consists of sections dealing with demographic data of the patient including age, sex, level of education, approximate yearly income, and relation to an interviewed family member. The next section deals with information about the disease that would be collected from the patient's chart by a trained nurse. The disease information includes the diagnosis, stage of the disease, date of diagnosis, and Eastern Cooperative Oncology Group performance status (ECOG).

The third section of the questionnaire will be completed through an interview conducted with the patient and one of his family members separately by the research assistants. The research assistants will be 
trained by the PI on communication skills regarding the appropriate manner and tone to be adopted to ask the questions without letting himself or the interviewee be overwhelmed with emotions and break down. The research assistant was not aware of the patients' diagnosis or his clinical condition to avoid influencing the patient or family member's responses. The interview questionnaire is divided into parts with separate columns for the patient and the family member. It contains detailed questions regarding the attitude of the patients and family members towards the method and process of the disclosure, the details of the disease, prognosis, and the preferred options including DNR and advances care plan practices. The patient and family member's awareness of the diagnosis, preference of the place of care, willingness to be informed about the diagnosis, timing of disclosure, appropriate person to disclose and receive the bad news were recorded. The experience of the patient about the mode of delivery of bad news and its appropriateness in terms of empathy towards the patient or family know about poor prognosis, Do Not Resuscitate (DNR) decision, and the preferred place of death. A separate space is assigned for the patient or the family member to write his or her suggestions for the scope of improvement in his experience with the staff. (Appendix 1)

\section{Ethical Approval:}

The patient and the family member will be informed about the study in detail before securing informed consent. Ethical clearance was obtained from the Institution Review Board before the study.

\section{Statistical Analysis:}

Age, Time since initial diagnosis and Income were the only three continuous variables from Sociodemographic data, that were presented as mean with standard deviation and the median. All other data structure for Cross Assessment in Patient and care-giver about Breaking Bad News, was having categorical characteristics, which was presented in frequencies and percentages. Concordance between the patient and the care giver opinions with regard to Breaking Bad News was measured by Kappa statistics. All statistical analyses were performed using SPSS 25.0 software (SPSS Inc., Chicago, IL, USA) package; two-tailed a p-value of 0.05 was considered significant.

\section{Results:}

A total of 149 patients and their family caregivers responded to the survey. However, each question had varying response rates as shown in the table (1). 


\begin{tabular}{|c|c|c|c|c|}
\hline & Valid 'N' & $\mathrm{N}(\%)$ & Mean $\pm D$ & $\begin{array}{l}\text { Median (min - } \\
\text { max) }\end{array}$ \\
\hline Age (yr) & 149 & & $47 \pm 17$ & $49(16-105)$ \\
\hline $\begin{array}{l}\text { Time since initial diagnosis } \\
\text { (month) }\end{array}$ & 148 & & $45 \pm 40$ & $36(3-216)$ \\
\hline Income (SR) & 78 & & $7513 \pm 5279$ & $\begin{array}{l}5000(2000- \\
36000)\end{array}$ \\
\hline Participants & Patient & 149(100.0) & & \\
\hline \multirow[t]{2}{*}{ Gender } & Female & $117(78.5)$ & & \\
\hline & Male & $32(21.5)$ & & \\
\hline \multirow[t]{6}{*}{ Education } & Diploma & $7(4.9)$ & & \\
\hline & High education & $2(1.4)$ & & \\
\hline & High school & $50(34.7)$ & & \\
\hline & Illiterate & $49(34.0)$ & & \\
\hline & $\begin{array}{l}\text { primary } \\
\text { Education }\end{array}$ & $1(.7)$ & & \\
\hline & University & $35(24.3)$ & & \\
\hline \multirow[t]{2}{*}{ Metastasis } & No & $91(62.8)$ & & \\
\hline & Yes & $54(37.2)$ & & \\
\hline \multirow[t]{2}{*}{ ECOG Score } & $0-2$ & $106(72.1)$ & & \\
\hline & $3-4$ & $41(27.9)$ & & \\
\hline
\end{tabular}

The average age of patients was $47 \pm 17$ years, $78.5 \%$ were Females and most were either high school graduates $(34.7 \%)$ or illiterate (34\%). $62.8 \%$ had localized disease and $72 \%$ were with a good performance status (ECOG 0-2).

Both patients (87.1\%) and family members (74.3\%) felt that the doctor (primary physician) who knows the accurate medical details should be the one to break the bad news. While $51.7 \%$ (75) of the patients felt that news is better delivered immediately, a large majority $73.9 \%$ (105) of the caregivers felt that it has to be done gradually. While a majority, $46.2 \%(66)$ of patients felt that waiting for the diagnostic results is the most stressful time, $45 \%$ (63) of the family members felt it was the time of the actual breaking bad news that was the hardest (Table2). 
$75.2 \%(109)$ of the patients felt that they should be informed of the bad news first, while an almost equal proportion of caregivers $72.9 \%$ (102) felt that the family should be informed before the patient. Both patients $(79 \%)$ and family members (83\%) wanted to know the full details of the diagnosis and prognosis of the disease. The patient reported diagnosis and the family reported diagnosis matched $90 \%$ of the times. While $37.2 \%$ (54) of patients truly had metastatic disease, only $20.9 \%(28)$ of the patients and $25.4 \%$ (34) of the family accurately knew about the metastatic disease status.

$75 \%$ (105) of patients wanted to be informed even if their disease were to become unresponsive to the treatment or progressed in the future (treatment failure). Only $56.1 \%$ (78) of the family members wanted disclosure of information regarding treatment failure (Table 2). 
Table 2: Cross Assessment in Patient and care-giver about Breaking Bad News

\begin{tabular}{|c|c|c|c|c|}
\hline & & Patient & Care-giver & $\begin{array}{l}\mathrm{p} \\
\text { value }\end{array}$ \\
\hline \multirow{3}{*}{$\begin{array}{l}\text { 1. The most appropriate person to } \\
\text { inform you about your diagnosis and } \\
\text { prognosis }\end{array}$} & Doctor & $128(87.1)$ & 104(74.3) & \multirow[t]{3}{*}{0.003} \\
\hline & Family & 19(12.9) & $36(25.7)$ & \\
\hline & Total & 147(100.0) & $140(100.0)$ & \\
\hline \multirow[t]{3}{*}{ 2. When to disclose } & Immediately & 75(51.7) & $37(26.1)$ & \multirow[t]{3}{*}{$<0.001$} \\
\hline & Gradually & $70(48.3)$ & 105(73.9) & \\
\hline & Total & 145(100.0) & 142(100.0) & \\
\hline \multirow[t]{5}{*}{$\begin{array}{l}\text { 3. What was the Hardest Stage of } \\
\text { breaking Bad news }\end{array}$} & $\begin{array}{l}\text { I did not find any } \\
\text { difficulty }\end{array}$ & $20(14.0)$ & $4(2.9)$ & \multirow[t]{5}{*}{0.496} \\
\hline & $\begin{array}{l}\text { Stage of } \\
\text { informing the } \\
\text { truth of the } \\
\text { diagnosis }\end{array}$ & $38(26.6)$ & $63(45.0)$ & \\
\hline & $\begin{array}{l}\text { Stage of } \\
\text { informing about } \\
\text { the plan of care }\end{array}$ & 19(13.3) & $20(14.3)$ & \\
\hline & $\begin{array}{l}\text { Waiting for the } \\
\text { results of the } \\
\text { diagnostic tests }\end{array}$ & $66(46.2)$ & $53(37.9)$ & \\
\hline & Total & 143(100.0) & 140(100.0) & \\
\hline \multirow[t]{4}{*}{ 4. Who should be informed first? } & Family & $35(24.1)$ & 102(72.9) & \multirow[t]{4}{*}{$<0.001$} \\
\hline & Patient & $109(75.2)$ & $34(24.3)$ & \\
\hline & $\begin{array}{l}\text { Patient and } \\
\text { Family }\end{array}$ & $1(.7)$ & $4(2.9)$ & \\
\hline & Total & 145(100.0) & 140(100.0) & \\
\hline \multirow[t]{4}{*}{$\begin{array}{l}\text { 5. How much of the Bad news do } \\
\text { you want to know? }\end{array}$} & $\begin{array}{l}\text { Diagnosis, } \\
\text { Prognosis, } \\
\text { treatment }\end{array}$ & $117(79.6)$ & $117(83.0)$ & \multirow[t]{4}{*}{1.000} \\
\hline & $\begin{array}{l}\text { Diagnosis and } \\
\text { treatment }\end{array}$ & $21(14.3)$ & 16(11.3) & \\
\hline & $\begin{array}{l}\text { I don't like to know } \\
\text { anything }\end{array}$ & $9(6.1)$ & $8(5.7)$ & \\
\hline & Total & 147(100.0) & $141(100.0)$ & \\
\hline $\begin{array}{l}\text { 6. Concordance between patient and } \\
\text { family member about the diagnosis. }\end{array}$ & Same & $95(90.5)$ & $95(90.5)$ & 1.000 \\
\hline
\end{tabular}




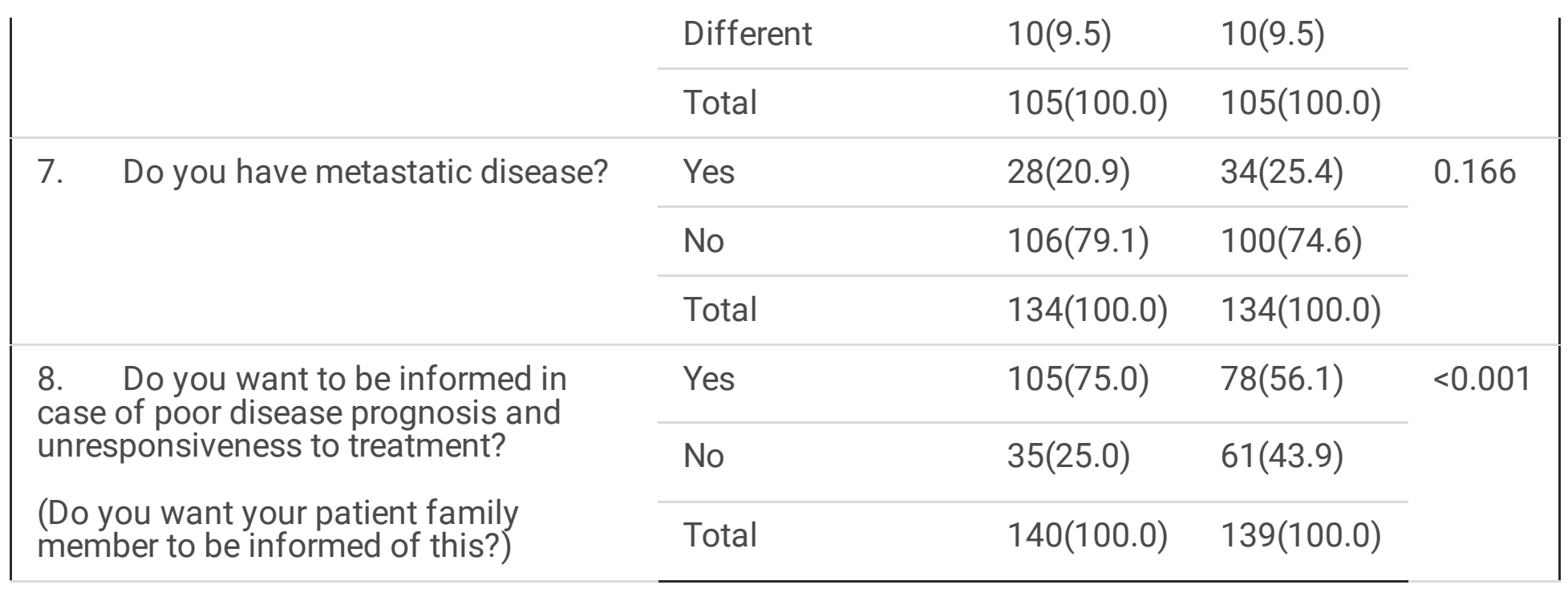

Most patients and family members had already received some bad news about their disease at the time of the survey. The majority of patients and family members felt that the doctor's clinic is the best place to break the bad news. The health care professionals had been empathetic while breaking bad news $82 \%$ of the time. $90 \%$ of the time, they were actively listening. $86 \%$ of the time, they handled the patient reactions well. Despite this, $55.9 \%$ (71) patients and $65.6 \%(80)$ family members felt that there can be a better way of communicating bad news. Breaking bad news was followed by a clear care plan and options $88 \%$ of the time (Table 3).

Interestingly, more caregivers $67.2 \%(78)$ had a strong emotional reaction to the bad news than patients $51.2 \%(63) .36 .6 \%(45)$ of the patients could accept the bad news. $48.9 \%(66)$ of patients and $49.6 \%(64)$ of the family members expressed initial shock and later on accepted the bad news (Table 3 ). 


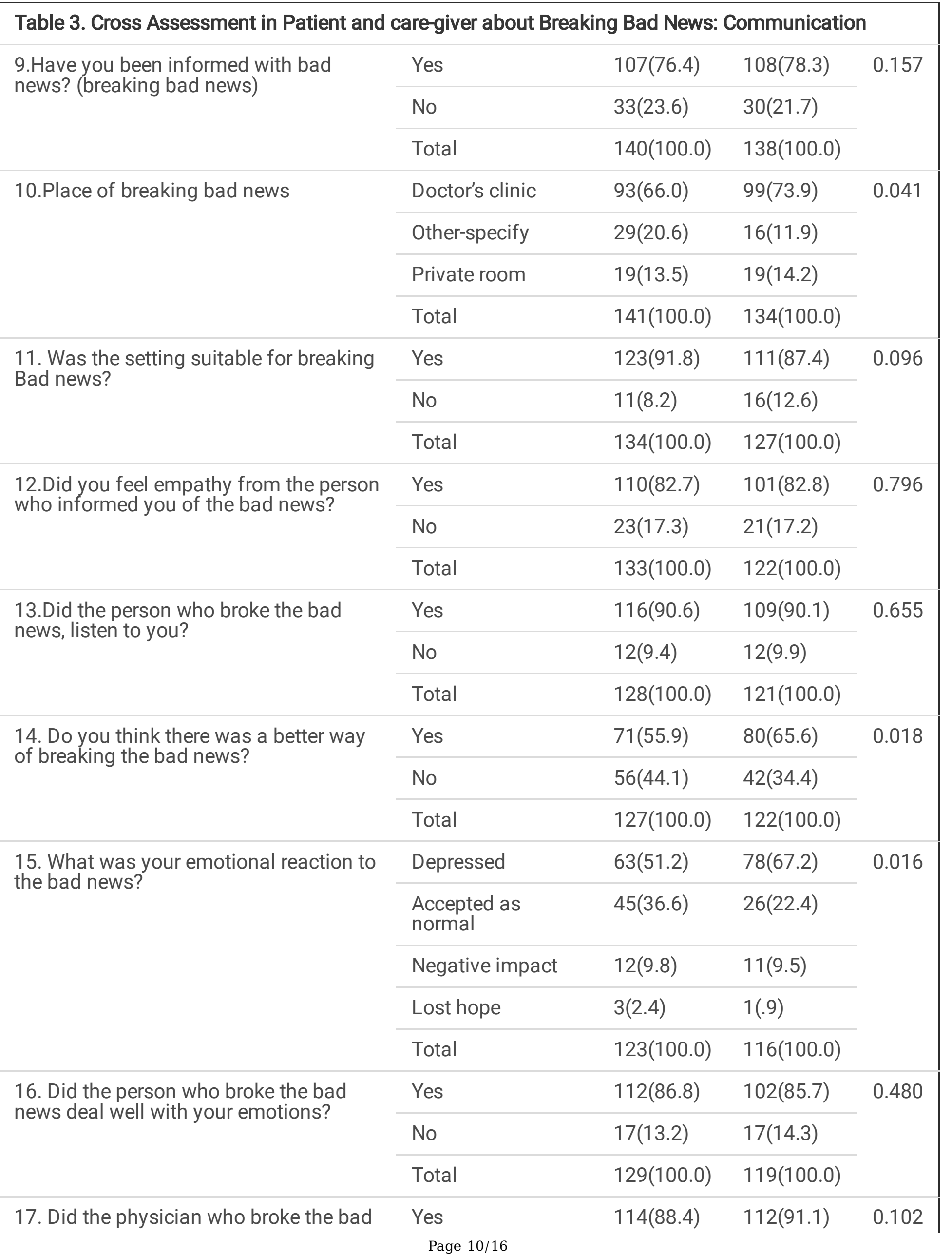




\begin{tabular}{|c|c|c|c|c|}
\hline \multirow[t]{2}{*}{$\begin{array}{l}\text { news provide you with the treatment } \\
\text { plan and available options? }\end{array}$} & No & 15(11.6) & $11(8.9)$ & \\
\hline & Total & 129(100.0) & 123(100.0) & \\
\hline \multirow[t]{5}{*}{$\begin{array}{l}\text { 18. What was the overall impact of } \\
\text { breaking bad news on you? }\end{array}$} & $\begin{array}{l}\text { Feeling better } \\
\text { because issues } \\
\text { were more clear }\end{array}$ & $32(23.7)$ & $22(17.1)$ & \multirow[t]{5}{*}{0.785} \\
\hline & Negative impact & $20(14.8)$ & $30(23.3)$ & \\
\hline & No impact & $17(12.6)$ & 13(10.1) & \\
\hline & $\begin{array}{l}\text { Shocking first then } \\
\text { changed }\end{array}$ & $66(48.9)$ & $64(49.6)$ & \\
\hline & Total & 135(100.0) & 129(100.0) & \\
\hline
\end{tabular}

The majority of patients (82\%) and family members had not heard about DNR at the time of the survey. $54.3 \%$ (75) of the patients and $71.4 \%$ (95) of the family members did not want DNR/no CPR/no ICU decisions to be discussed with them (Table 4).

While $59.7 \%$ (83) of patients opted for home as the preferred place of care, a slightly lower percent of family members $54.1 \%$ (72) wanted home to be the place of care. $45 \%(60)$ of the family members chose the hospital to be the place of care for the patients. $50 \%$ (64) of the patients and only $33.3 \%(43)$ of family members preferred home over the hospital as an appropriate place of death (Table 4). 


\begin{tabular}{|c|c|c|c|c|}
\hline \multirow[t]{3}{*}{ 19. Are you familiar with DNR } & Yes & $24(17.3)$ & $36(26.9)$ & \multirow[t]{3}{*}{0.020} \\
\hline & No & $115(82.7)$ & $98(73.1)$ & \\
\hline & Total & 139(100.0) & 134(100.0) & \\
\hline \multirow{3}{*}{$\begin{array}{l}\text { 20. Do you want to know the physician's decision } \\
\text { for NO CPR, NO ICU if your condition } \\
\text { deteriorated? }\end{array}$} & Yes & $63(45.7)$ & $38(28.6)$ & \multirow[t]{3}{*}{0.001} \\
\hline & No & $75(54.3)$ & $95(71.4)$ & \\
\hline & Total & 138(100.0) & 133(100.0) & \\
\hline \multirow{4}{*}{$\begin{array}{l}\text { 21. Place of care in case of general health } \\
\text { deterioration }\end{array}$} & Home & $83(59.7)$ & $72(54.1)$ & \multirow[t]{4}{*}{0.423} \\
\hline & Hospital & $56(40.3)$ & $60(45.1)$ & \\
\hline & $\begin{array}{l}\text { Not } \\
\text { applicable }\end{array}$ & $0(.0)$ & $1(.8)$ & \\
\hline & Total & 139(100.0) & 133(100.0) & \\
\hline \multirow[t]{4}{*}{ 22. Place of Death } & Home & $64(50.0)$ & 43(33.3) & \multirow[t]{4}{*}{0.006} \\
\hline & Hospital & $60(46.9)$ & $83(64.3)$ & \\
\hline & $\begin{array}{l}\text { Not } \\
\text { applicable }\end{array}$ & $4(3.1)$ & $3(2.3)$ & \\
\hline & Total & $128(100.0)$ & $129(100.0)$ & \\
\hline
\end{tabular}

The concordance between the responses of the patient and family member were analyzed. We observed that a moderate level of mutual agreement was met with 7 questions [Q2, Q5, Q8, Q19, Q20, Q21, and Q22] that varied between $60 \%$ to $74 \%$. These questions $(2,5,8)$ related to the timing and how much of the bad news, patients, and families wanted to be disclosed. Questions 19,20,21,22 related to advance care planning - about DNR, place of care, and death.

The agreement in response was $64.5 \%$ for timing, $72.7 \%$ for "How much of the Bad news to disclose" and $68.9 \%$ for disclosure in care of progressive disease/poor prognosis/failure of treatment. The agreement in response was $72.5 \%$ for knowledge about DNR, $64.4 \%$ for disclosure about no CPR/no ICU, $70 \%$ for a place of care, and $68.3 \%$ for a place of death.

\section{Discussion:}

A good number of patients and their caregivers felt that there could be a better way of delivering bad news. This is even though the majority expressed that the breaking bad news was done mostly in a safe setting (hospital/doctor's clinic), it was done with sensitivity, active listening, empathy, and completed with a clear care plan. Further research into communication of bad news is required to explore the 
specific needs of the Saudi population in order to bridge the gap in their satisfaction with the current quality of communicating bad news.

In our study, we found some interesting similarities and differences in attitude between patients and families regarding truth-telling. While most Saudi patients wanted to know the full details of the diagnosis and prognosis including details of treatment failure, family members tried to protect the patient from the potentially harmful bad news. This difference became clear especially when discussion about treatment failure had to be made. This study showed that the Saudi family member has more negative reactions upon hearing bad news compared to the patients themselves. The family members have to be supported equally, if not more during the process of breaking bad news. The finding that the period of waiting for the diagnostic test results being the hardest is also a significant area for improvement. Patients felt this more than the family members. Patients have to be given a clear time frame about when to expect the results and be actively supported during this waiting period. While most western patients would be willing to freely discuss the end of life decisions like DNR/no CPR, only $45 \%$ of Saudi patients in our study wanted to discuss such details. This is significant because unlike in the west, in Saudi Arabia DNR is a medical decision and has to be communicated sensitively to the patient and caregivers. More than half of them might not want to talk about DNR and end-of-life issues. The gap between patient and caregiver preferences about the place of care and more important place of death is also a very important area for improvement. While more patients (than their family members) preferred to die at home, about $50 \%$ of them wanted to die at the hospital. Better education and awareness about the positives of home death assisted by good home care is important to close this gap to suit the patient's wishes.

The findings of this study revealed a moderate concordance between the responses of the patients and their family members in the important domains relating to breaking bad news and advance care planning. The agreement in response was $64.5 \%$ for timing, $72.7 \%$ for "How much of the Bad news to disclose" and $68.9 \%$ for disclosure in care of progressive disease/poor prognosis/failure of treatment. The agreement in response was $72.5 \%$ for knowledge about DNR, $64.4 \%$ for disclosure about no CPR/no ICU, $70 \%$ for a place of care, and $68.3 \%$ for a place of death. This shows that the patients and family members did not differ much in their opinions and the conflict was minimal.

Based on our research findings we propose a breaking bad news system (figure 1) wherein the advance care planning information is gathered at the time of registration in the health care system. Specifically, to what extent the patient wants to know about their illness, especially, about poor prognosis, significant end-of-life care decisions, DNR, and place of death. Information about patient proxy and the extent of the proxy's involvement in decision making should be documented from the patient. This could be done by a trained health educator or allied health care specialists like a social worker or spiritual educator.

Breaking bad news support must start at the time of investigation for serious illness with effective communication, psychological, social, and spiritual support to manage the stress and anxiety of the patient and family. Patient and family wishes and needs have to be explored and understood. Bad news should be delivered by the primary physician using SPIKES or any other standard communication tool. 


\section{Conclusion:}

Though there are significant differences between patient and family members regarding full disclosure of diagnosis and prognosis especially, end of life issues like DNR and place of death, we found moderate concordance in their responses which show a minimal difference in opinion between them. Patients and families were not fully aware of their metastatic disease status. Family members may be emotionally more affected than patients. Both patients and family members require better education and support during breaking bad news. The most stressful time for the patient was waiting for confirmatory test results. Therefore, we propose that breaking bad news systems and support services should systematically begin even before diagnostic investigations begin. Our study points out that the majority of patients want to know the full details of diagnosis and prognosis. Discussion regarding code status has to be more structured in a way that the patient and family do not feel abandoned due to the Do Not Resuscitate status. Further study is needed to study the necessity and efficacy of a breaking bad news system in the hospital.

\section{Declarations:}

Conflict of interest: All the authors declare that there is no conflict of interest.

1. Ethics approval and consent to participate - Yes. KFMC institutional Review Board approved the study. Written Informed consent was secured was obtained from all participants. Verbal explanations and consent was obtained from those who could not read due to any reason.

2. Consent for publication - Not applicable. Participant's identity was kept confidential throughout the study. This is not a clinical trial/study.

3. Availability of Data and Materials - Available upon request from the authors. This is not a clinical study or trial.

4. Competing interests - none

5. Funding - Institutional intramural funding

6. Authors' contributions

MA - concept and development of framework.

BD - Manuscript writing.

Both authors have read and approved the manuscript.

7. Acknowledgements - The authors would like to acknowledge the Research and Scientific writing Department of KFMC for their valuable input regarding statistical analysis and manuscript preparation.

\section{References:}


1. Zekri JM, Karim SM, Bassi S, Sadiq B, Abdelghany EM, et al. (2015) Breaking Bad News: Preferences of Cancer Patients in Saudi Arabia. J Palliat Care Med 5: 207.

2. Yun Y H, Lee C G, Kim S, Lee S, Heo D S, Kim J S, et all. The Attitudes of Cancer Patients and Their Families Toward the Disclosure of Terminal Illness. Clin Oncol 22:307-314 (2004)

3. Buckman R. Breaking bad news: Why is it still so difficult? Br Med J. 1984; 288:1597-9.

4. Vaidya VU, Greenberg LW, Patel KM, Strauss LH, Pollack MM. Teaching physicians how to break bad news: A 1-day workshop using standardized parents. Arch PediatrAdolesc Med. 1999;153: 419-22.

5. Peteet JR, Abrams HE, Ross DM, et al: Presenting a diagnosis of cancer: Patients' views. J Fam Pract 32:577-581, 1991

6. Sapir R, Catane R, Kaufman B, et al: Cancer patient expectations of and communication with oncologists and oncology nurses: The experience of an integrated oncology and palliative care service. Support care cancer 8:458-463, 2000

7. Smith TJ, Swisher K: Telling the truth about terminal cancer. JAMA 279:1746-1748, 1998

8. Ajaj A, Singh MP, Abdulla AJJ: Should elderly patients be told they have cancer? Questionnaire survey of older people. BMJ 323:1160, 2001

9. Jenkins V, Fallowfield L, Saul J: Information needs of patients with cancer: Results from a large study in UK cancer centres. Br J Cancer 84:48-51, 2001

10. Parker PA, Baile WF, Moor CM, et al: Breaking bad news about cancer: Patients' preferences for communication. J Clin Oncol 19: 2049-2056, 2001

11. Ptacek JJ: Patients' perceptions of receiving bad news about cancer. J Clin Oncol 19:4160-4164, 2001

12. Bain M G, Lian C W, Thon C C. Breaking bad news of cancer diagnosis - Perception of the cancer patients in a rural community in Malaysia. South Asian J Cancer. 2014 Apr-Jun; 3(2): 116-121.

13. Fallowfield L, Jenkins V. Communicating sad, bad, and difficult news in medicine. Lancet 2004;363:312-9.

14. Fallowfield LJ, Jenkins VA, Beveridge HA. Truth may hurt but deceit hurts more: communication in palliative care. Palliat Med. 2002;16:297-303

15. Fielding RG, Hung J. Preferences for information and involvement in decisions during cancer care among a Hong Kong Chinese population. Psycho-Oncology. 1996;5:321-29. [Google Scholar]

16. Berger JT. Culture and ethnicity in clinical care. Arch Intern Med. 1998;158:2085-2090. [PubMed] [Google Scholar]

17. Uchitomi Y, Yamawaki S. Truth telling practice in cancer care in Japan. Ann NY Acad Sci. 1997;809:290-99. [PubMed] [Google Scholar]

18. Annas G. Informed consent, cancer and truth in prognosis. N Engl J Med. 1994;330:223-5. [PubMed] [Google Scholar]

19. Sykes J, Johnson R, Hanks GW, Fallon M, O'Neill B. ABC of Palliative Care. Communication with patients, families and professionals. N Engl J Med. 1998;330:223-5. [Google Scholar] 


\section{Figures}

\section{All patients within the health care system shall be asked about their wishes about full disclosure}

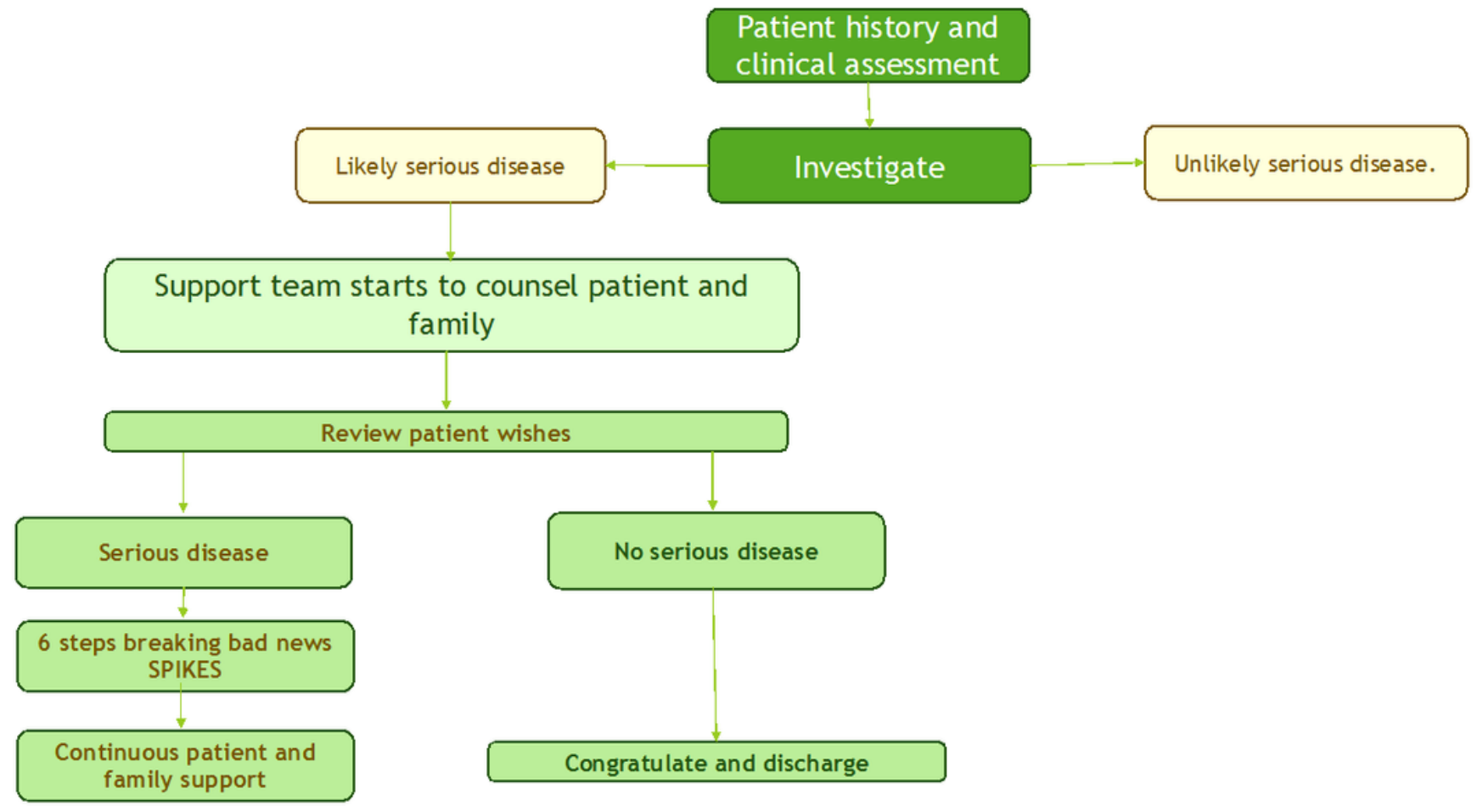

\section{Figure 1}

Breaking Bad News System

\section{Supplementary Files}

This is a list of supplementary files associated with this preprint. Click to download.

- Appendixquestionnaire.docx 